\title{
The Teaching Innovation of Higher Education in the Post-Epidemic Era
}

\author{
Yingxia Luo, Zaiqian Qi*, Bai Li \\ Beijing Union University, Beijing 100101, China \\ *Corresponding author: Zaiqian Qi, Idtyingxia@buu.edu.cn
}

\begin{abstract}
COVID-19 has triggered an upsurge of research on the reform of higher education teaching mode. Based on the analysis of the main problems and experiences of online teaching in colleges and universities during the epidemic period, this article emphasizes on the innovation of higher education teaching reform in the post-epidemic era from five aspects which are the teaching objectives, contents, methods, modes, and priorities in order to provide ideas and become a reference for global education reform.
\end{abstract}

Keywords: Online education; Post-epidemic era; Courses; Teaching innovation

Publication date: July 2021; Online publication: July 30, 2021

\section{Introduction}

In 2020, the unexpected COVID-19 greatly impacted the social development and the traditional operation mode of higher education. Large-scale online teaching became the main form of an emergency teaching mode. According to the statistics of The United Nations Educational, Scientific and Cultural Organization (UNESCO), more than 200 countries around the world have implemented different degrees of online teaching. As the founder of "no class suspension," China stated at a press conference held by the Ministry of Education on May 14, 2020, that 1.07 million higher education courses are opened nationwide, covering 17.75 million online learning college students ${ }^{[1]}$. The impact of the epidemic on higher education is not only on the reversal of the mode of teaching but it also deeply affected the education concept and value. On the basis of summarizing and analyzing the experiences and shortcomings during the epidemic period, this article explores innovation and reform of higher education curriculum teaching in the post-epidemic era.

\section{Main issues}

\subsection{Modern information technology does not meet the needs of teaching}

The epidemic situation makes people realize that modern information technology has played an unprecedented role in teaching. However, compared with the improvement of people's daily lives by digitization, networking, and intellectualization, the support and change of modern information technology for education are obviously lagging behind. During the epidemic period, although countries have maximized the online learning needs of their people through network, television, and other means, there are still many shortcomings in the network support, online teaching resources, and online education technology. According to reports, less than $60 \%$ of students in some countries have access to the internet. There is a huge gap in the online virtual simulation software, especially in engineering and in the supply of network resources of many disciplines and levels in addition to an extremely unbalanced information 
literacy among teachers and students. Therefore, on the basis of adhering to the essence of education, there is still more room for improvement in the effective use of modern information technology in order to promote the teaching quality and efficiency.

\subsection{Online teaching paradigm does not meet the needs of students' development}

During the epidemic period, whether live or through social network, the online teaching still holds on to the "mono" teaching form. The depth and breadth of network interaction between teachers and students are generally inadequate which is difficult to promote solutions for key and difficult issues in teaching. In the implementation of a student-centered education concept with the promotion of students' active learning, cooperative learning, and inquiry learning, the students' sense of acquisition and the design of teaching activities are poor in addition to the need to improve the teaching effect.

\subsection{Gaps between online resources and the needs of talent training}

During the epidemic period, due to recording in advance or emergency production of online teaching videos, it is difficult to reflect the teaching contents while keeping pace with the times. At the same time, in order to support a wider range of sharing, the professionalism of online teaching resources has to be greatly reduced. The excessive use of limited resources is likely to lead to the homogenization of higher education around the world, resulting in the blurring, weakening, and even the disappearing of the concept of heterogeneity and cultural characteristics ${ }^{[3]}$.

\section{Advantages of online teaching in the epidemic situation}

\subsection{Improvement of information literacy among teachers and students}

During the epidemic period, in view of the large-scale online teaching emergency, it became a great exercise for teachers and students in regard to online teaching technology and ability. For example, in order to meet the needs of teaching, teachers from the Beijing Union University actively tried to diversify the online teaching mode where they designed some thinking problems and small exercises in combination with the contents of teaching videos to test their students' learning effect. On the other hand, some teachers guided students to write in English along with the video contents in order to achieve the purpose of applying what they have learned. Some even tried to use a variety of online technologies in classes, developed virtual experiment teaching software, and so on. At the same time, in the process of participating in learning, students gradually mastered the skill of using the relevant online teaching platforms. The information technology and information literacy of teachers and students have improved unprecedentedly.

\subsection{Teachers' reform consciousness has been strengthened}

The epidemic situation allowed teachers to appreciate the infinite potential of the internet. More and more teachers began to combine traditional teaching with online teaching, contemplated about efficient classroom and deep learning based on the network, re-examined the personalized learning needs and the precise allocation of high-quality resources, and paid more attention to subject integration and the suitability of teaching contents to the era. Teachers have also begun to ponder about the values and goals of education in addition to implementing the reform of classroom teaching. The enhancement of teachers' reform consciousness has laid an important foundation for the reform of teaching innovation in the post-epidemic era. 


\section{Focus of the higher education curriculum teaching reform in the post-epidemic era}

\subsection{Paying more attention to moral cultivation in the teaching objectives}

Throughout the ancient and modern world, whether it is the "six arts" in ancient China, Aristotle's thoughts in ancient Western countries, the ideas of many subsequent educators such as Comenius and Robert Owen, or the regulations of the current Chinese education authorities, the core goals of education are reflected in three aspects which are "morality, intelligence, and physique" where the most important one is moral education. The connotation of moral education is broad which not only refers to moral quality, but it also refers to political attitude, ideological consciousness, and reflective consciousness of the educated. In today's era of great social change and turbulence, there is a need for more people with great morality, love, and feelings, who can cherish their country and the world, shoulder the responsibility of building the country, sharing their worries, as well as promoting world peace and development. As the fundamental task of colleges and universities, it is of great historical significance to establish morality and cultivate people. The implementation of moral education should not rely on empty slogans but on the "drip irrigation" of every course. It needs to be further strengthened in the teaching objectives of courses.

\subsection{Paying more attention to the integration of multi-disciplines in the teaching content}

In order to achieve the goal of an all-rounded development in terms of morality, intelligence, sports, beauty, and labor in the new era, the selection and construction of teaching contents are very important. At present, Chinese colleges and universities are striving to build all kinds of "golden courses" with construction standards that are high-level, innovative, and challenging. The so-called "high-level" standard is to cultivate students' comprehensive ability and advanced thinking to solve complex problems. The term "innovative" refers to the frontiers and times of the curriculum contents in addition to an advanced and interactive teaching form while the learning results are exploratory and personalized. "Challenging" refers to the difficulty of the course which requires a leap. In this way, there are higher requirements for teachers and students in the preparation of lessons and after class, respectively. It is impossible to achieve the above requirements without the support of a multi-disciplinary teaching content. The large-scale spread of the epidemic reminded people not to ignore the education content of human and nature, as well as life and responsibility. In the face of complex and changeable international situations such as anti-globalization and the rapid development of new science and technology, curriculum reform needs to deeply promote interdisciplinarity, discipline-opening, industry-university-research integration, collaborative innovation, and international cooperation, so as to cultivate compound high-quality talents with sufficient ability to cope with the changing environment ${ }^{[5]}$.

\subsection{Paying more attention to the cultivation of students' sustainable growth ability in the emphasis of course teaching}

Dewey pointed out in his article that the purpose of education is to cultivate people's ability of sustainable growth ${ }^{[6]}$. How then to cultivate it? The first is to grasp the ability category of human's sustainable growth and the second is to take effective measures. Bloom divided students' cognitive level from low to high into memory, understanding, application, analysis, evaluation, and creation. He believes that students are more likely to connect and integrate the elements of knowledge through the construction in a more complex high level learning process such as analysis, evaluation, and creation, so as to achieve significant learning results. According to the Future of Jobs Report 2020 released by the World Economic Forum, the categories of skills that employees would generally lack in the next five years include critical thinking and analysis, problem-solving, as well as self-management such as resilience and flexibility. At the same time, the report forecasts the top three skills that the global job market requires the most in 2025; namely, analytical thinking 
and innovation, active learning and learning strategies, as well as complex problem-solving. These skills undoubtedly belong to the category of people's ability for sustainable growth. In addition, existing survey showed that $94 \%$ of enterprise managers think that employees need to update their skills urgently, and about $40 \%$ of employees require skill-training every six months (or even shorter). As the futurist, Alvin Toffler said, "The illiterate of the future is no longer the illiterate, but the one who has not learned to learn." As a basic skill of the citizens in the new era, autonomous learning ability is receiving much more attention.

\subsection{Paying more attention to the integration and innovation of online and offline teaching in the curriculum teaching methods}

The epidemic situation is the catalyst of the rapid change of higher education. All kinds of creative attempts of online teaching during the epidemic period have enriched the cognition of teaching forms, teaching and learning realization modes, and also provided opportunities to re-examine various possibilities of integrating technology into education ${ }^{[7]}$. After tasting the "sweetness" of online teaching, course teaching can no longer return to the traditional single way. The school of the future is a new education model for the fourth industrial revolution which redefines high-quality learning in the new economy, and it includes eight learning reform propositions which are personalized and self-paced learning, barrier-free and inclusive learning, problem-based and collaborative learning, as well as lifelong and student-driven learning which urgently needs the deep support of modern information technology. The organic integration of online and offline teaching to innovate teaching methods have made it more effective through competition, experiential, personification, diversification, and other ways to cultivate new people of the times. The hybrid mode of online and offline teaching still needs to follow the idea of the outcome-based education (OBE) with learning as the center and students as the main body while giving full play to the complementary advantages to achieve the educational goals. This requires teachers to continue to improve their information literacy, seriously study the curriculum and teaching methods, invest more energy to innovate the curriculum design, and deeply promote the interaction with their students in order to stimulate their learning interest, participation, and satisfaction. Universities and the society should vigorously support the construction of network teaching hardware facilities, and at the same time, teachers as well as researchers should be strongly supported to develop and enrich the network teaching resources, make up for the shortage of scarce resources such as virtual simulation experiments, and increase the co-construction as well as sharing of all kinds of teaching resources to a certain extent.

\subsection{Paying more attention to foreign exchange and cooperation in the curriculum teaching mode}

The online teaching during the epidemic period has promoted the cooperation among universities, enterprises, and governments, as well as the global sharing of teaching resources. The UNESCO representative in China said that the pace of building partnerships between national and local governments, as well as the private sector and civil society in China is amazing. These partnerships provide more channels for the dissemination of learning resources, such as live broadcast through television and social media. During the epidemic period, Tsinghua University offered more than 300 massive open online courses (MOOCs) to the whole society without any charges and China's Ministry of Education launched the construction project of the international online teaching platform for colleges and universities. The British Council for culture and education has set up branch websites for 113 countries and regions. Knowledge is the wealth of mankind. In the era of a shared future community for mankind, the value of unity, cooperation, and common development is highlighted. Colleges and universities need to break through the restrictions of physical space and personnel flow, make full use of modern information technology, and actively explore new forms as well as new modes of international curriculum construction in order to benefit more people 
in the process of seeking knowledge and wisdom.

\section{Conclusion}

Curriculum is the core element of talent training where the quality of curriculum directly determines the quality of talent training. There is no end to curriculum reform, and now, it is a good time. The epidemic situation has stimulated reform ideas and expanded the reform vision to speed up the global curriculum reform and provide more intellectual support for the cultivation of "new" people of the times.

\section{Funding}

Educational Teaching Research and Reform Project by Beijing Union University: Research on How to Improve the Quality of Constructed Tourism Management Curriculum (Project no.: JJ2021Y022).

\section{Disclosure statement}

The authors declare that there is no conflict of interest.

\section{References}

[1] Pan Q, Hu Y, Que M, 2020, Challenge and Innovation of Higher Education Teaching Mode in "Post Epidemic Era" - Interview with Professor Ulrich, A World-Famous Expert in Higher Education Research. Fudan Education Forum, (6): 10-6.

[2] Dan J, Chen Q, 2021, Global Education Reform in the Post Epidemic Era: A Summary of the 20th Annual Conference of Comparative Education Branch of Chinese Society of Education. Comparative Education Research, (3): 102-7.

[3] Yang B, 2020, Full Release of "Anti-Epidemic Dividend": Promoting Education Reform and Innovation. Education Research of Tsinghua University, (3): 1-5, 33.

[4] Bo Y, Ren B, 1986, History of Western Education, People's Education Press. 